\title{
Direct synthesis of Al-SBA-15 containing aluminosilicate species plugs in an acid-free medium and structural adjustment by hydrothermal post-treatment
}

\author{
Lei Shi ${ }^{\mathrm{a}}$, Yan Xu ${ }^{\mathrm{b}, \mathrm{c}, 1}, \mathrm{Na}$ Zhang ${ }^{\mathrm{a}}$, Sen Lin ${ }^{\mathrm{b}, *}$, Xiangping $\mathrm{Li}^{\mathrm{b}}$, Peng Guo ${ }^{\mathrm{b}}$, Xuebing $\mathrm{Li}^{\mathrm{b}}$ \\ ${ }^{a}$ Key Laboratory of Fine Chemicals in Universities of Shandong, Shandong Polytechnic University, Daxue Road, Changqing District, Jinan 250353, China \\ ${ }^{\mathrm{b}}$ Qingdao Institute of Bioenergy and Bioprocess Technology, Chinese Academy of Sciences, No. 189 Songling Road, Laoshan District, Qingdao 266101, China \\ ${ }^{\mathrm{c}}$ Institute of Petrochemical Technology, Changzhou University, Gehu Road, Changzhou 213164, China
}

\section{A R T I C L E I N F O}

\section{Article history:}

Received 15 February 2013

Received in revised form 17 April 2013

Accepted 28 April 2013

Available online 7 May 2013

\section{Keywords:}

Mesoporous Al-SBA-15

Aluminosilicate plugs

Eco-friendly synthesis

Structural adjustment

Hydrothermal post-treatment

\begin{abstract}
A B S T R A C T
A series of Al-SBA-15 with controllable aluminosilicate plug structures inside straight mesopores has been hydrothermally synthesized in a one-step synthesis in an environmentally friendly acid-free medium, using triblock copolymer Pluronic P123 as a structure-directing agent, water as solvent, tetraethyl orthosilicate (TEOS) and aluminum nitrate $\left(\mathrm{Al}(\mathrm{NO})_{3} \cdot 9 \mathrm{H}_{2} \mathrm{O}\right)$ as silica and aluminum sources, respectively. The effects of the P123/Si molar ratio in the initial solution and aging temperature on the structural properties of the resulting materials were investigated by powder X-ray diffraction (XRD), nitrogen adsorption-desorption at $77 \mathrm{~K}$, transmission electron microscopy (TEM), scanning electron microscopy (SEM), thermogravimetric (TG), FT-IR spectra and inductively coupled plasma (ICP) analyses. The nature of the $\mathrm{Al}$ species and the acidity of the resultant samples were studied by solid state ${ }^{27} \mathrm{Al}$ MAS NMR and pyridine adsorption measurements. The specific surface area $\left(935-755 \mathrm{~m}^{2} \mathrm{~g}^{-1}\right)$, pore volume $\left(1.03-0.56 \mathrm{~cm}^{3} \mathrm{~g}^{-1}\right)$ and especially the concentration and distribution of open type mesopores (0-68\% to the total pores) of the synthesized Al-SBA- 15 can be controlled by a simple adjustment of the P123/Si molar ratio in the initial solution. Moreover, increasing the aging temperature higher than $363 \mathrm{~K}$ can remarkably decrease the formation of plug structures to obtain "open" form mesopores. The observation by TEM of alternate defined gray and white areas inside the mesopores gives the strong evidence of isolated microporous aluminosilicate plugs inside the channels. In addition, a moderate hydrothermal post-treatment can finely modify the mesostructures through the partial or complete dissolution of the aluminosilicate plugs.
\end{abstract}

(c) 2013 Elsevier Inc. All rights reserved.

\section{Introduction}

Thanks to the regular array of pores with uniform diameter from a few to tens of nanometers, ordered mesoporous materials have significant potential applications in selective adsorption, separation, nanocasting, drug delivery, and electronics [1-7]. Among the reported mesoporous materials, SBA-15, using block copolymers poly(ethylene oxide)-poly(propylene oxide)-poly(ethylene oxide) $\left(\mathrm{EO}_{20} \mathrm{PO}_{70} \mathrm{EO}_{20}\right.$, Pluronic P123) as structural directing agent, which has two-dimensional (2-D) hexagonal p6mm symmetry and channel-type mesopores, has attracted much attention due to its wider pore size and considerably thicker pore walls than MCM-41 $[8,9]$. It has a better thermal and hydrothermal stability and has been regarded as the most competitive candidate for the

\footnotetext{
* Corresponding author. Fax: +86 53280662778.

E-mail address: linsen@qibebt.ac.cn (S. Lin).

1 The author contributed equally to this work.
}

bulk conversion of molecules [10,11]. In recent years, the work has focused on the synthesis of SBA-15 type mesoporous materials with high stability, active sites capacity and improved channel net, through environmentally friendly and highly controllable routes [12].

It has been reported that microporous materials containing hierarchical pore structures can be synthesized through the aggregation of nanoparticles [13-16]. Following this synthetic strategy, a series of mesoporous materials with bimodal mesopores can be prepared. For instance, Zhang et al. tailored framework and textural mesopores of HMS by controlling the polarity of the reaction medium [17]. Ikari et al. reported a bimodal architecture of mesoporous silica consisting small $(2-3 \mathrm{~nm})$ and large (10-100 $\mathrm{nm})$ mesopores by varying the concentrations of cationic surfactants and ammonia [18]. Meanwhile, Wang et al. obtained textural mesopores with a narrow pore size distribution in the range of $12-35 \mathrm{~nm}$ in the synthesis of xerogel through a two-phase sol-gel process [19]. As for the SBA-15 type mesoporous materials, Zhang et al. synthesized SBA-15 type materials with a framework 
large pore of $\sim 30 \mathrm{~nm}$ and a small pore of $5-10 \mathrm{~nm}$ in diameter by a solution sol-gel approach with the aid of a swelling agent [20]. The mesoporous materials aforementioned showed a relatively broad textural mesopore distribution since it was formed by physical aggregation of silica sources. Therefore, devising a facile and controllable method to synthesize SBA-15 type mesoporous material which possesses a hierarchical pore structure with a narrow size distribution still remains a challenge.

Recently, a novel pore structure with porous plugs within the mesopores was reported; it can be obtained in the strong acidic synthesis system which is widely used for the preparation of SBA15 by simply increasing of the amount of the silica source in the reaction mixture [21-23]. The resulting mesoporous materials exhibited both high stability and uniform mesostructures. Jia et al. synthesized plug-containing Al-SBA-15 materials by introducing toluene and aluminum precursors into the traditional SBA-15 synthesis [24]. Wu et al. synthesized an aluminumcontaining plugged SBA-15 from an aqueous nitrate solution with the P123/Si molar ratio of 0.017 . The synthesis was carried out in a weak acidic medium with the aid of the hydrolysis of aluminum nitrate salt $[25,26]$. MCM-41 with similar partially plugged mesopores was prepared with an ammoniacal hydrothermal posttreatment approach as reported by Yuan et al [27]. The excellent hydrothermal stability and high thermal stability of this kind of silicon-based mesoporous material (usually referred to as plugged hexagonal template silicas, PHTS) was attributed to the existence of porous plug structures inside the mesopores [22]. Characteristically, these materials principally exhibit a two-step desorption isotherm branch due to the pore blocking. However, there is still a lack of direct evidence to prove the existence of these plug structures in the mesopores. The synthesis of PHTS materials is also mainly limited to that of silicon-based mesoporous materials [28], which are of limited use for catalytic applications as they lack active sites [2]. Moreover, uncertainties remain over the formation mechanism and properties of plug structures $[29,30]$.

In this paper, we report the direct synthesis of Al-SBA-15 with tunable aluminosilicate plug structures inside the straight mesopores, through a facile adjustment of organic template concentration in an acid-free medium. The effect of aging temperature on the structural properties of plug-containing Al-SBA-15 was studied to understand the formation of the plug structures under the weak acidic synthetic system. Most importantly, the plug structures located in the mesopores were imaged by TEM for the first time. We would like to note that acid-free synthetic method is very efficient on the formation of highly structural ordered Al-SBA-15 under a very low surfactant concentration in the initial reaction mixture. The resulting sample exhibited highly structural stability and flexibility on the tuning of pore structure. Additionally, the structural properties of plug-containing Al-SBA-15 can be further finely modified through a moderate hydrothermal post-treatment method via the partial or total dissolution of the aluminosilicate plug.

\section{Materials and method}

\subsection{Synthesis of Al-SBA-15 in the absence of acid}

Al-SBA-15 was prepared using a nonionic triblock copolymer, Pluronic P123 (Aldrich), as the structure-directing agent. Tetraethyl orthosilicate (TEOS, Sinopharm Chemical Reagent Co., Ltd.) and aluminum nitrate 9-hydrate $\left(\mathrm{Al}\left(\mathrm{NO}_{3}\right)_{3} \cdot 9 \mathrm{H}_{2} \mathrm{O}\right.$, Sinopharm Chemical Reagent Co., Ltd.) were used as silica and aluminum sources, respectively. All reagents were used as received.

In this study, the influence of the P123/Si molar ratio and aging temperature on the structural properties of the final samples was investigated. The samples were synthesized from the initial reaction solutions with different P123/Si molar ratios of 0.014 (sample S1), 0.010 (sample S2), 0.0075 (sample S3), 0.0050 (sample S4), and 0.0025 (sample S5). In order to further investigate the aluminosilicate plug structures inside the straight mesopores, the aging temperature was varied from $343 \mathrm{~K}$ (sample S6) to $383 \mathrm{~K}$ (sample S7) and $403 \mathrm{~K}$ (sample S8) followed the synthetic conditions of S4 (P123/Si molar ratio of 0.0050$)$.

The Al-SBA-15 samples were synthesized following the method reported previously [31]. In a typical synthesis, the required amount of P123 was dissolved in $81 \mathrm{~mL}$ of water under magnetic stirring for a few hours at room temperature, after which the $0.615 \mathrm{~g}$ of $\mathrm{Al}\left(\mathrm{NO}_{3}\right)_{3} \cdot 9 \mathrm{H}_{2} \mathrm{O}$ was added into the gel and the mixture was further stirred for $0.5 \mathrm{~h}$. Then, $6.85 \mathrm{~g}$ of TEOS was added to the clear solution and the mixture was kept under vigorous stirring for another $15 \mathrm{~h}$ at room temperature. Subsequently, the mixture was kept at $313 \mathrm{~K}$ for $24 \mathrm{~h}$ under stirring and then transferred to an autoclave and heated at different aging temperatures for 2 days under static conditions. The solid precipitate was recovered by filtration, washed several times with distilled water, and dried at $333 \mathrm{~K}$ overnight. To remove the surfactant, the solid was first calcined in air at $423 \mathrm{~K}$ for $1 \mathrm{~h}$ ( $3 \mathrm{~K} \mathrm{~min}^{-1}$ heating rate), and then at $823 \mathrm{~K}$ ( $3 \mathrm{~K} \mathrm{~min}^{-1}$ heating rate) for another $5 \mathrm{~h}$.

\subsection{Test of hydrothermal stability}

All calcined samples were mixed with distilled water in the proportion of $0.5 \mathrm{~g} / 100 \mathrm{~mL}$. The open beaker containing the mixture was placed in an oven and maintained at $373 \mathrm{~K}$ for $100 \mathrm{~h}$, with the periodical (every $8 \mathrm{~h}$ ) addition of water. The solid product was filtered, washed and dried at $333 \mathrm{~K}$ in an air atmosphere overnight. The resulting materials have an extra "-ht" in the designation.

\subsection{Characterization}

X-ray diffraction (XRD) measurements were carried out on a Bruker AXS-D8 Advance powder diffractometer, using $\mathrm{Cu} \mathrm{K} \alpha$ radiation $(40 \mathrm{kV}, 40 \mathrm{~mA})$, with a step size of $0.02^{\circ}(2 \theta)$ and $2 \mathrm{~s}$ per step over the $2 \theta$ range from $0.5^{\circ}$ to $8^{\circ}$. Unit cell parameters were calculated using at least 2 peaks. The nitrogen adsorptiondesorption isotherms at $77 \mathrm{~K}$ were determined on an Autosorb ${ }^{\mathbb{R}}$ $6 B$ instrument, using nitrogen of $99.999 \%$ purity. Prior to the experiments, the samples were outgassed for $6 \mathrm{~h}$ at $453 \mathrm{~K}$, achieved using a heating rate of $1 \mathrm{~K} \mathrm{~min}^{-1}$. The total specific surface areas were calculated by the Brunauer-Emmett-Teller (BET) method, while the external specific surface areas and the specific pore volumes, were obtained by the $\alpha_{\mathrm{s}}$ method, using standard data for adsorption of nitrogen on non-porous partially hydroxylated silica to construct the $\alpha_{\mathrm{s}}$ plots. Mesopore diameters were obtained from the maximum of the pore size distributions (PSD) calculated from the adsorption branch and equilibrium model by the nonlocal density functional theory (NLDFT) method, using the software QuadraWin ${ }^{\mathrm{TM}}$ from Quantachrome. Scanning electron microscopy (SEM) was recorded on a Hitachi H-4800 microscope. Transmission electron microscopy (TEM) studies were carried out on a Hitachi H-7650 electron microscope with an accelerating voltage of $100 \mathrm{kV}$. The Si/Al molar ratios of the final calcined materials were determined from Optima 2000DV instrument. Infrared spectra were recorded on a Nicolet iZ10. ${ }^{27} \mathrm{Al}$ MAS NMR spectrum was recorded on a Bruker Avance 400 spectrometer at $104.3 \mathrm{MHz}$. For acidity studies, the selected calcined plugcontaining Al-SBA-15 was pressed into thin wafer $\left(10 \mathrm{mg} / \mathrm{cm}^{2}\right)$ and active in situ in the cell at $673 \mathrm{~K}$ for $4 \mathrm{~h}$ in vacuum $\left(<10^{-3}\right.$ Torr $)$ and then cooled to room temperature (293 $\mathrm{K}$ in this work), followed by the saturated adsorption of pyridine. After evacuated 
the cell to $<10^{-3}$ Torr, the spectra were recorded on a Nicolet/ NEXUS-470 spectrometer.

\section{Results and discussion}

As seen in Fig. 1a, the XRD patterns of all calcined Al-SBA-15 samples exhibit at least two well-resolved peaks which can be indexed to the (100) and (200) reflections associated with the p6mm hexagonal symmetry, indicating that well-ordered mesostructures were obtained. The structure regularity improved with increasing amounts of polymeric template added in initial reaction solution; this is supported by the occurrence of a third intense reflection peak assigned to (110) reflection. In addition, the peak indexed to the (100) reflection shifts slightly to lower angle with higher concentrations of P123, suggesting the unit-cell size of the final material is increase in respect to the P123/Si molar ratio (Table 1).
The Si/Al molar ratios (32-49) in the resulting materials varied with different quantitative amounts of P123 added (Table 1) when keeping a Si/Al molar ratio in the initial solution unchanged. The acidity generated from the hydrolysis of the metal salts in water allowed the formation of mesostructures with the long-range order [32,33] $\mathrm{pH}$ values were measured for all samples at each synthetic step. For example, the pH value of the P123 solution was around 7.2 and dropped to 3.7 after dissolution of aluminum nitrate. With the addition of TEOS and aging at room temperature (around $293 \mathrm{~K}$ in this work) for $15 \mathrm{~h}$, the $\mathrm{pH}$ value of the mixture dropped to 2.5. In such a case, the self-generated acidity from the hydrolysis of aluminum nitrate was probably effective for the hydrolysis of TEOS. It is well known that the precipitation of silica gel would not take place in the synthetic solution with a $\mathrm{pH}$ value above 2 (the isoelectric point of silica) [34]. Moreover, the $\mathrm{pH}$ value of the mixture hydrothermally treated at $313 \mathrm{~K}$ for $24 \mathrm{~h}$ was around 2.2, which suggested that aluminum can also influence the self-assembly of the micelle-inorganic aggregates. It is noted
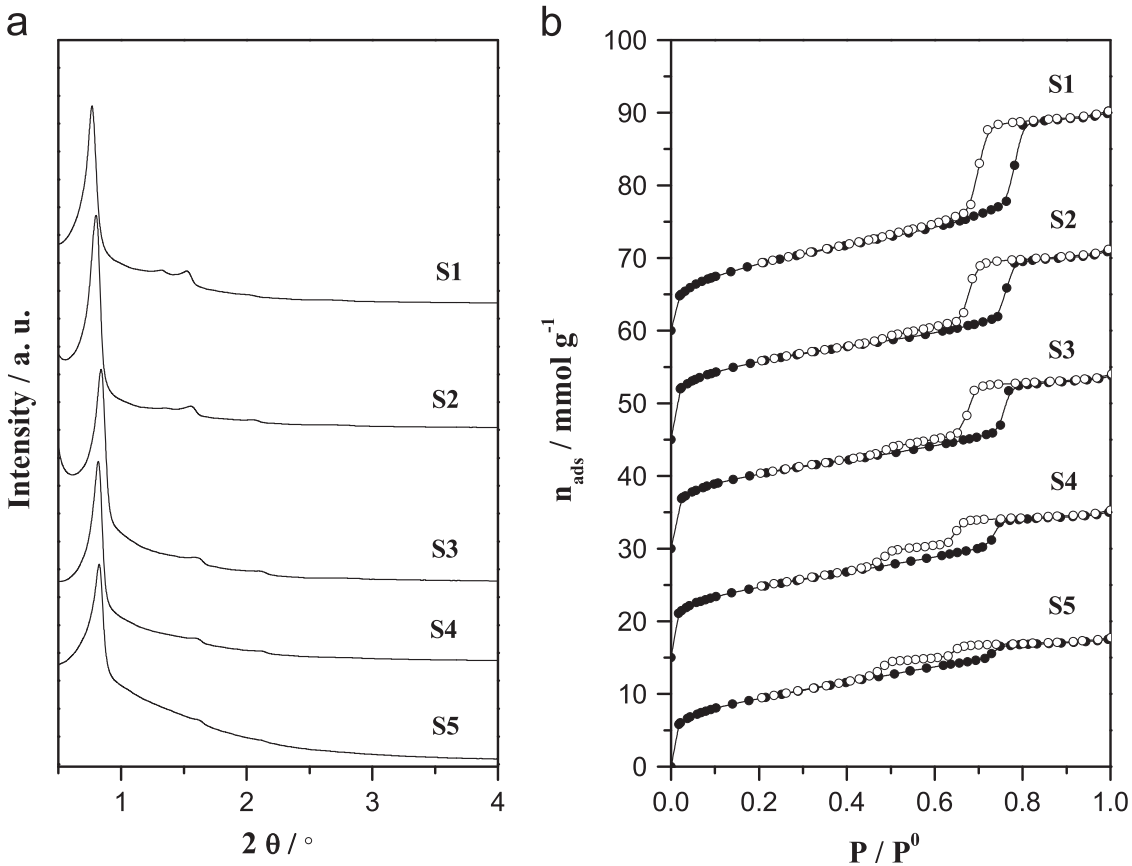

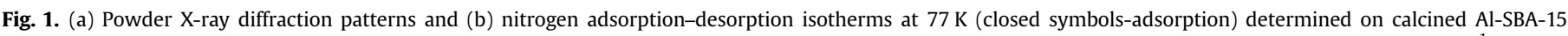
synthesized, without addition mineral acid, at $363 \mathrm{~K}$ and with different P123/Si molar ratios. The isotherms were offset vertically by 15 , 30,45 , and $60 \mathrm{mmol} \mathrm{g}^{-1}$.

Table 1

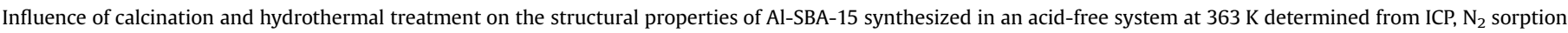
and XRD data.

\begin{tabular}{|c|c|c|c|c|c|c|c|c|c|c|c|c|c|c|}
\hline Sample & $\begin{array}{l}\mathrm{Si} / \\
\mathrm{Al}\end{array}$ & $\begin{array}{l}\mathrm{P} 123 / \\
\mathrm{Si}\end{array}$ & $\begin{array}{l}a_{0} \\
(\mathrm{~nm})\end{array}$ & $\begin{array}{l}A_{\mathrm{BET}} \\
\left(\mathrm{m}^{2} \mathrm{~g}^{-1}\right)\end{array}$ & $\begin{array}{l}A_{\mathrm{ext}} \\
\left(\mathrm{m}^{2} \mathrm{~g}^{-1}\right)\end{array}$ & $\begin{array}{l}V_{p} \\
\left(\mathrm{~cm}^{3} \mathrm{~g}^{-1}\right)\end{array}$ & $\begin{array}{l}V_{\text {mic }} \\
\left(\mathrm{cm}^{3} \mathrm{~g}^{-1}\right)\end{array}$ & $\begin{array}{l}V_{\text {mes }} \\
\left(\mathrm{cm}^{3} \mathrm{~g}^{-1}\right)\end{array}$ & $\begin{array}{l}V_{\text {mes, blocked }} \\
\left(\mathrm{cm}^{3} \mathrm{~g}^{-1}\right)\end{array}$ & $\begin{array}{l}V_{\text {mes, open }} \\
\left(\mathrm{cm}^{3} \mathrm{~g}^{-1}\right)\end{array}$ & $\begin{array}{l}V_{\text {micro }} \\
(\%)\end{array}$ & $\begin{array}{l}V_{\text {mes, blocked }} \\
(\%)\end{array}$ & $\begin{array}{l}D_{p} \\
(\mathrm{~nm})\end{array}$ & $\begin{array}{l}t \\
(\mathrm{~nm})\end{array}$ \\
\hline S1 & 34 & 0.014 & 12.5 & 935 & 45 & 1.03 & 0.12 & 0.91 & 0 & 0.91 & 12 & 0 & 8.1 & 4.4 \\
\hline S2 & 32 & 0.010 & 12.3 & 865 & 44 & 0.82 & 0.15 & 0.67 & 0.15 & 0.52 & 18 & 22 & 7.6 & 4.7 \\
\hline S3 & 49 & 0.0075 & 12.0 & 823 & 38 & 0.75 & 0.13 & 0.62 & 0.20 & 0.42 & 17 & 32 & 7.6 & 4.4 \\
\hline S4 & 44 & 0.0050 & 12.0 & 780 & 30 & 0.64 & 0.10 & 0.54 & 0.31 & 0.23 & 16 & 57 & 7.3 & 4.7 \\
\hline S5 & 32 & 0.0025 & 12.0 & 755 & 27 & 0.56 & 0.03 & 0.53 & 0.36 & 0.17 & 5 & 68 & 7.3 & 4.7 \\
\hline S1-ht & 24 & 0.014 & 12.1 & 768 & 73 & 1.02 & 0 & 1.02 & 0 & 1.02 & 0 & 0 & 8.5 & 3.6 \\
\hline S2-ht & 35 & 0.010 & 12.2 & 748 & 89 & 1.05 & 0 & 1.05 & 0 & 1.05 & 0 & 0 & 8.5 & 3.7 \\
\hline S3-ht & 35 & 0.0075 & 12.1 & 711 & 63 & 0.91 & 0 & 0.91 & 0 & 1.05 & 0 & 0 & 8.5 & 3.6 \\
\hline S4-ht & 27 & 0.0050 & 11.7 & 708 & 49 & 0.84 & 0 & 0.84 & 0.25 & 0.59 & 0 & 30 & 8.1 & 3.6 \\
\hline S5-ht & 27 & 0.0025 & 12.0 & 647 & 37 & 0.57 & 0.01 & 0.56 & 0.24 & 0.32 & 2 & 43 & 7.3 & 4.7 \\
\hline
\end{tabular}

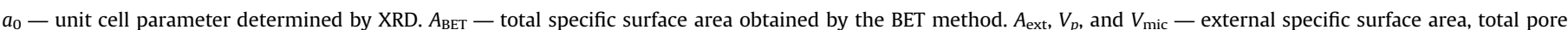

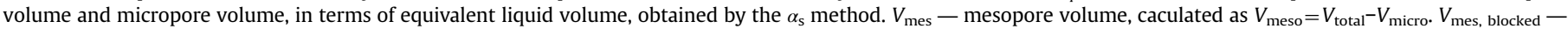

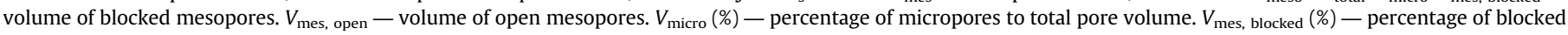

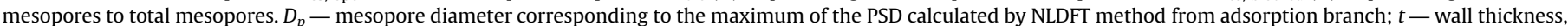
calculated as $t=a_{0}-D_{p}$. 

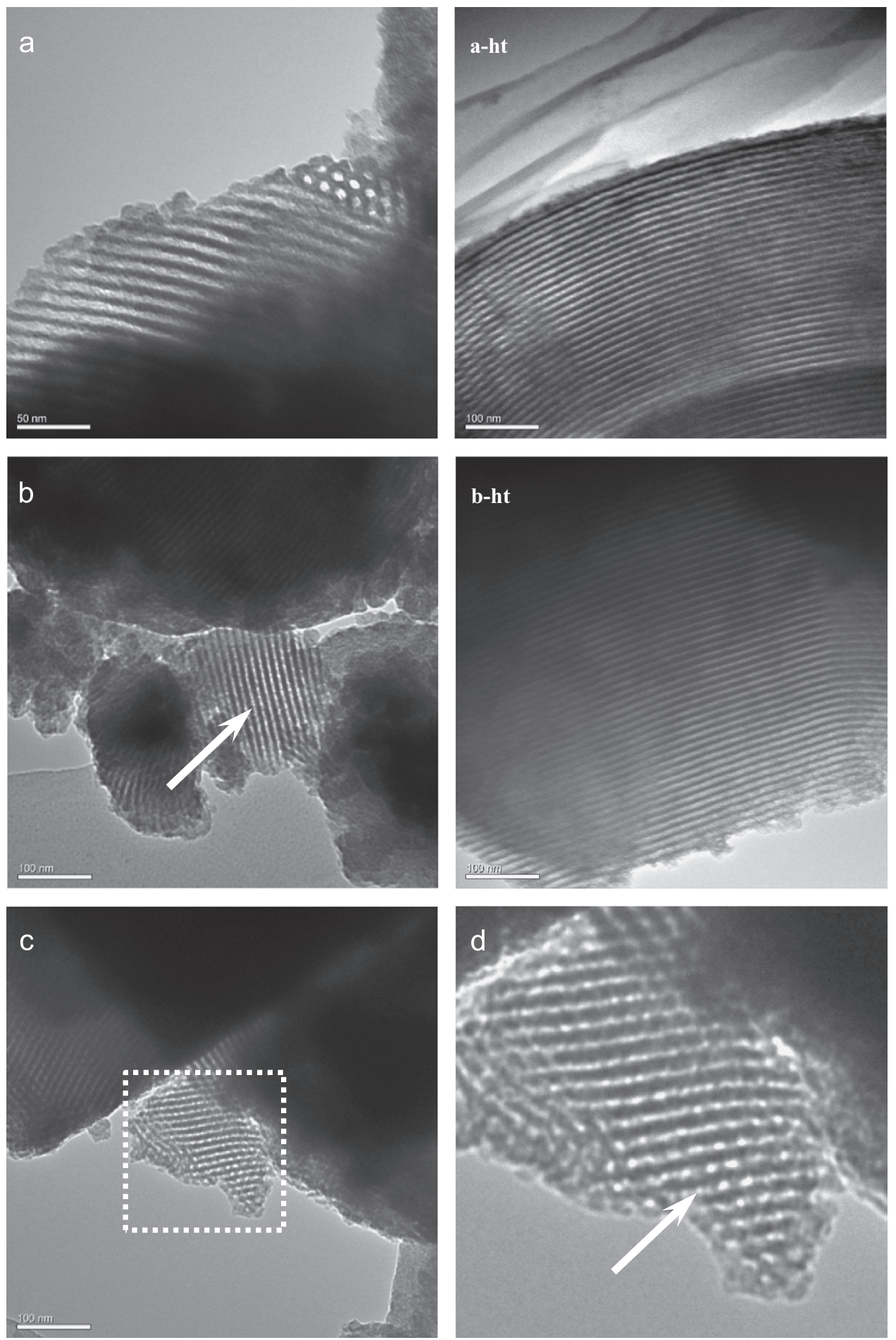

Fig. 2. Typical TEM images taken along the [110] directions of calcined Al-SBA-15, synthesized at different P123/Si molar ratios of (a) 0.014 ; (b) 0.0050 and corresponding samples hydrothermally treated in a boiling water for $100 \mathrm{~h}$ with a extra "-ht" in the designation of (a-ht) and (b-ht); (c) 0.0025 in the initial solution, and (d) the zooming-in image of the inside of dotted square within (c) showing the presence of plug aluminosilicate species inside the straight mesopores (see arrow).

that all the pH values aforementioned were independent of P123 concentrations in the synthesis. As the $\mathrm{pH}$ value of the initial solutions with various $\mathrm{P} 123 / \mathrm{Si}$ molar ratios is constant, the hydrolysis of TEOS should proceed similarly and form in the same structures. Therefore to account for the structural diversity observed in this study, it is reasonable to speculate that the competition between the deposition and dissolution back into the liquid phase of the silica species on to the polymeric micelles is altered by the simultaneous condensation of alumina.
As shown in SI Figs. 2 and 3, the nature of the $\mathrm{Al}$ species and the acidity of the resultant samples were studied by solid state ${ }^{27} \mathrm{Al}$ MAS NMR and pyridine adsorption measurements. The ${ }^{27} \mathrm{Al}$ MAS NMR spectra of selected plug-containing Al-SBA-15 (S4) synthesized without addition of mineral acid show two peaks centered at around 54 and $0 \mathrm{ppm}$. The $54 \mathrm{ppm}$ resonance is attributed to $\mathrm{Al}$ in a tetrahedral coordination (AlO4 structural unit, $\mathrm{Al}($ tet)), while the $0 \mathrm{ppm}$ peak is assigned to six-coordinated $\mathrm{Al}$ (AlO6 structural unit, $\mathrm{Al}(\mathrm{oct})$ ). The $\mathrm{Al}(4) / \mathrm{Al}(6)$ ratio is 5.0 , indicating the presence of 
predominantly 4-coordinated $\mathrm{Al}$ in the final samples. On the other hand, in Py-IR spectra on the same sample calcined at different temperature of $823 \mathrm{~K}$ and $973 \mathrm{~K}$, samples exhibit $1547 \mathrm{~cm}^{-1}$, and $1447 \mathrm{~cm}^{-1}$ band due to the Brönsted and Lewis acid sites, respectively (SI Fig. 3). The stronger $1447 \mathrm{~cm}^{-1}$ band for the sample calcined at $973 \mathrm{~K}$ is due to the formation of a larger amount of extra-framework aluminum during the calcination.

Nitrogen sorption isotherms for the calcined Al-SBA-15 samples shown in Fig. 1b are all type IV of the IUPAC classification with

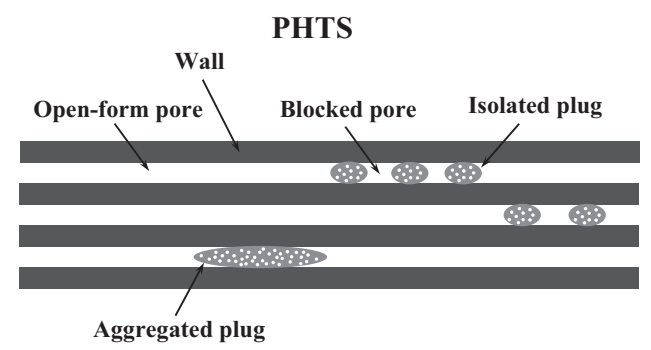

Fig. 3. Schematic drawing of plug-containing Al-SBA-15 synthesized without addition of any mineral acid.
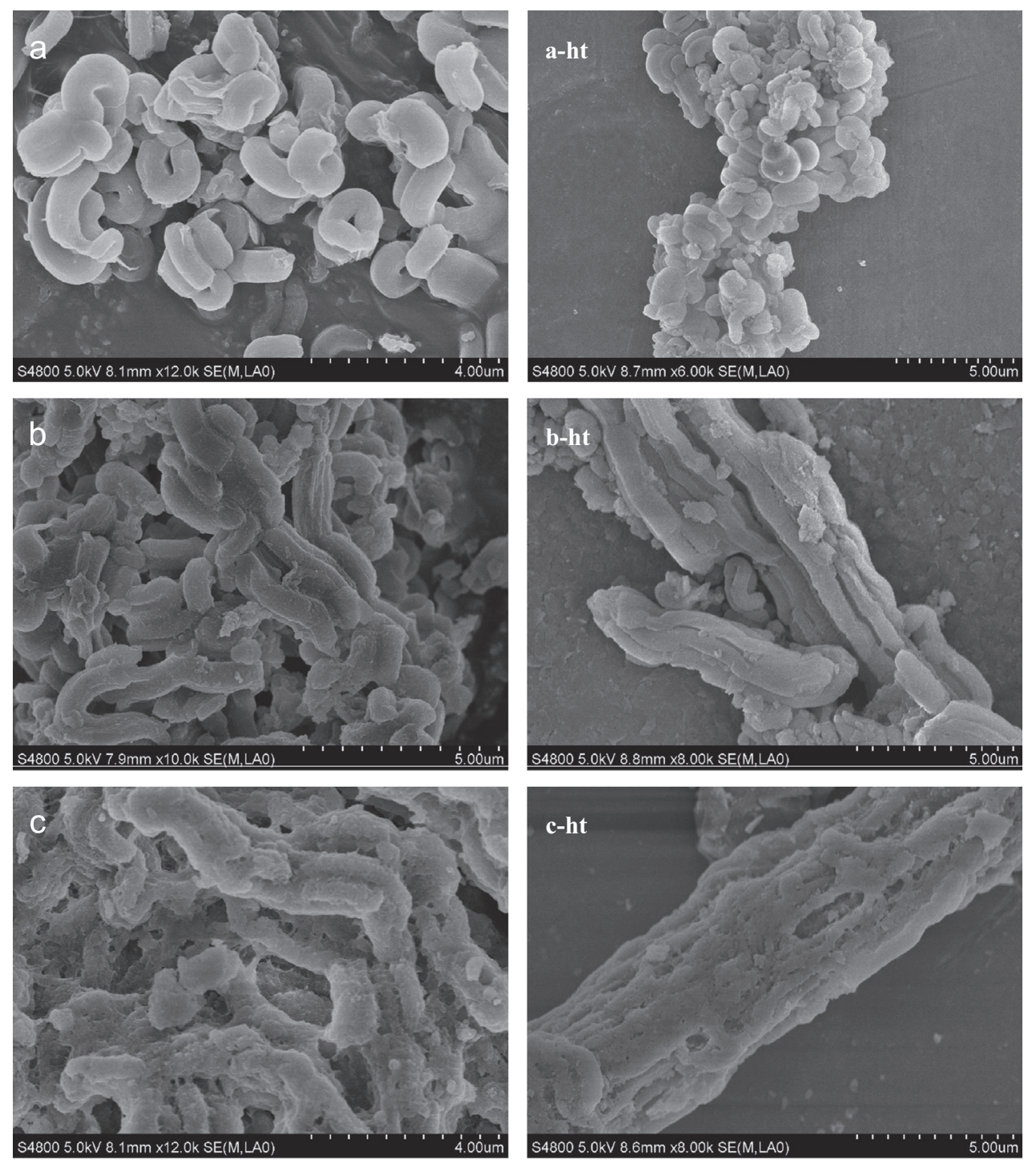

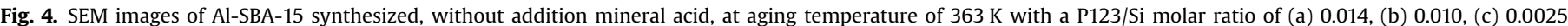
and corresponding samples hydrothermally treated in boiling water for $100 \mathrm{~h}$, designated with an extra "-ht".

a sharp capillary condensation step indicative of a narrow mesopore size distribution. The highly parallel adsorption and desorption branches in the hysteresis loops indicate that all samples possess uniform mesopores. The hysteresis loop with a two-step desorption branch gradually changed to a pure H1 type with increasing P123/Si molar ratio from 0.0025 to 0.014 . Particularly, the shift of capillary condensation to a higher relative pressure with the increase of $\mathrm{P} 123 / \mathrm{Si}$ molar ratio in the initial reaction solution from 0.010 to 0.014 is in accord with an increase in the mesopore size from 7.6 to $8.1 \mathrm{~nm}$ (Table 1). This result confirms that the pore size of Al-SBA-15 can be easily tailored by a judicious choice of the ratio of polymeric template/silica source under the synthetic conditions used in this work. When P123/Si molar ratio was reduced to 0.0075 , a steep capillary condensation combined with a clear two-step desorption was observed (S3). The first step on the desorption branch was attributed to the emptying of the "open" form mesopores, while the second step might be related to the $\mathrm{N}_{2}$ evaporation from the "blocked" mesopores through micropores or small mesopores inside the aluminosilicate plugs [22]. However, with decreased P123/Si molar ratios to 0.0050 and 0.0025 , the hysteresis loop closed at 0.44 of relative pressure. A careful study of the hysteresis loop showed that all hysteresis loops closed at $\mathrm{P} / \mathrm{P}^{0} \approx 0.45$, corresponding to the low limit of

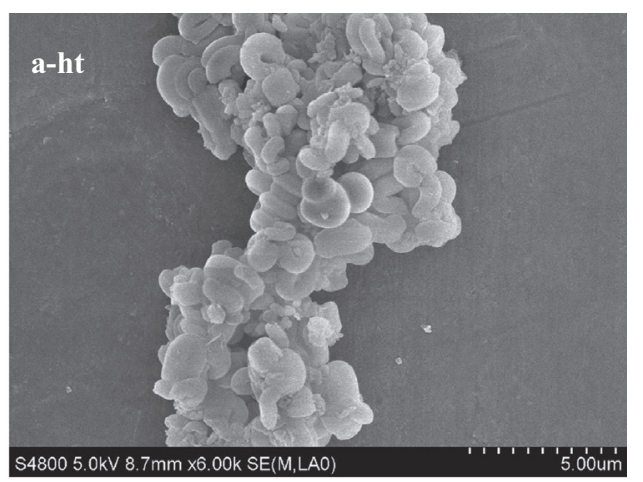


stability of liquid $\mathrm{N}_{2}$. As a consequence, we propose that our materials show the evaporation of adsorptive via a hemispherical meniscus as reported by Kruk et al. and Jun et al. [29,35].

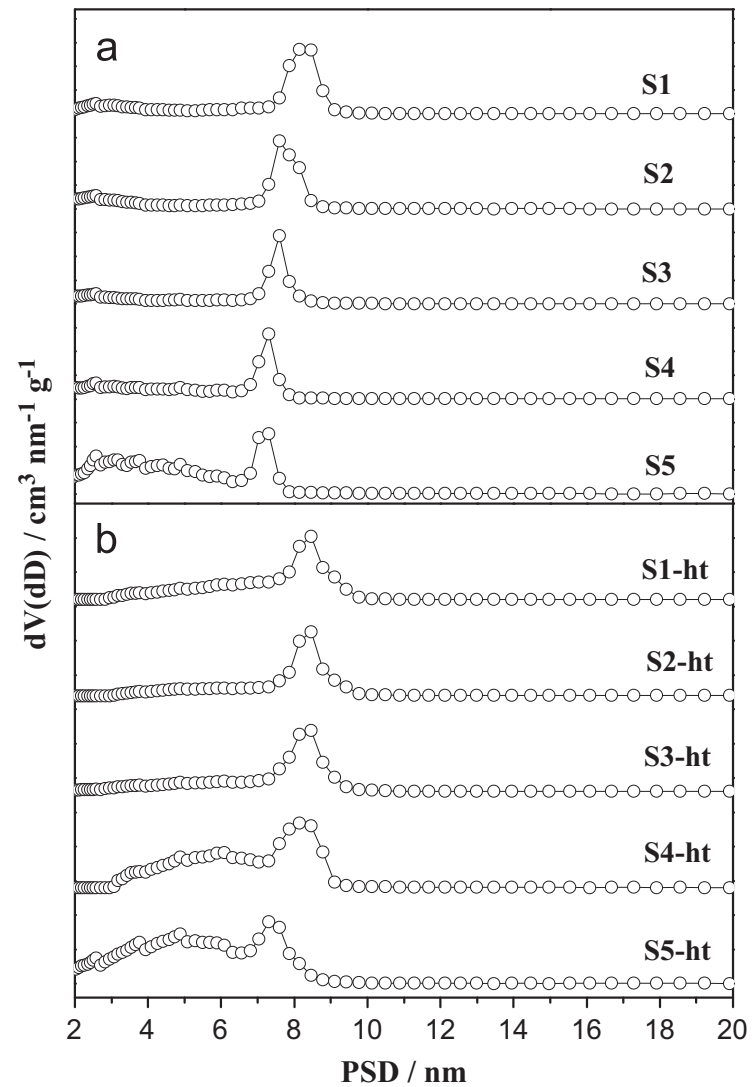

Fig. 5. NLDFT pore size distribution curves calculated from adsorption branches of (a) calcined Al-SBA-15 and (b) calcined Al-SBA-15 after hydrothermal treatment in boiling water for $100 \mathrm{~h}$.
Fig. 2 displays typical transmission electron microscopy (TEM) images taken along the 1D channel of SBA-15 for all prepared Al-SBA-15 in this work regardless of the P123/Si molar ratio in the initial reaction mixture. The wall and pores in the images are shown as dark and white stripes, respectively. The observation of uniform mesopores with one-dimensional channels confirms the high ordering of S1 (Fig. 2a), which hydrothermally treated from a reaction solution with a P123/Si molar ratio of 0.014 . With a P123/ Si molar ratio lowered to 0.0050 , some particles with a lower contrast inside the straight mesopores can be observed (see the arrow in Fig. 2b). A further decrease of the P123/Si molar ratio to 0.0025 results in a larger amount of fillers inside the mesopores (Fig. 2d). We interpret these areas of lower contrast in the channels as the imaging of the aluminosilicate plugs. The difference in contrast with the walls of the mesopores indicates that the plugs are not as dense as the walls and could be of a microporous nature [21]. The hole-like structures can be interpreted as the distribution of individual isolated plugs along the mesoporous channel (see schematic drawing in Fig. 3). The size of individual plugs was measured to be similar to that of the wall thickness $(4-5 \mathrm{~nm})$. We believe that our TEM images give the strong evidence of the existence of possibly microporous plugs inside the straight mesopores of SBA-15 materials. As reported by Van Der Voort, the formation of these plug species was related to the excess TEOS in the initial solution [21,22]. It is very likely that it is the presence of plugs in channels that causes the absence of the (110) diffraction peak in the XRD patterns of S4 and S5 (Fig. 1a), instead of a poorer ordering.

The textural properties of Al-SBA-15 samples are summarized in Table 1 . The reduction of P123/Si molar ratio from 0.014 to 0.0025 led to the decrease of BET surface area from 935 to $755 \mathrm{~m}^{2} \mathrm{~g}^{-1}$ and pore volume from 1.03 to $0.56 \mathrm{~cm}^{3} \mathrm{~g}^{-1}$. The micropore volume of $0.12 \mathrm{~cm}^{3} \mathrm{~g}^{-1}$ for $\mathrm{S} 1$ is generated from the superior penetration of PEO blocks into the silica wall during synthesis and subsequent calcinations as reported by other researchers [10,11,36-39]. Meanwhile, a constant decrease of micropore volume from 0.15 to $0.10 \mathrm{~cm}^{3} \mathrm{~g}^{-1}$ was observed with a

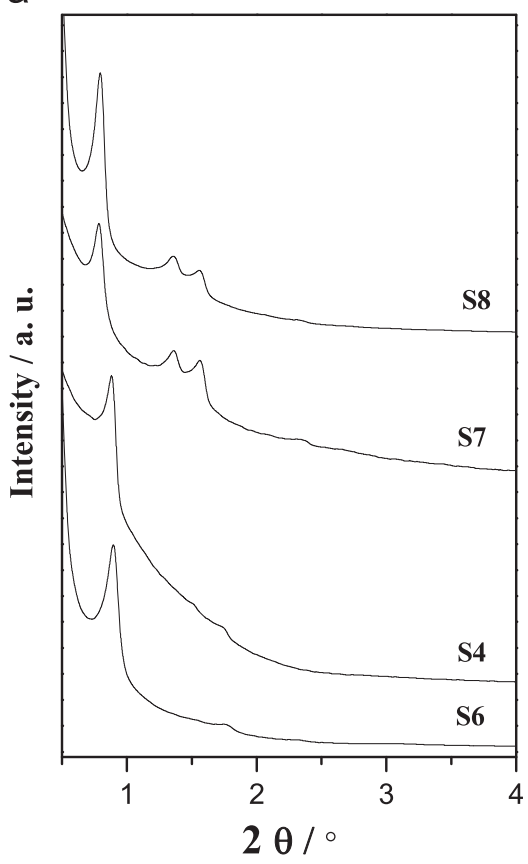

b

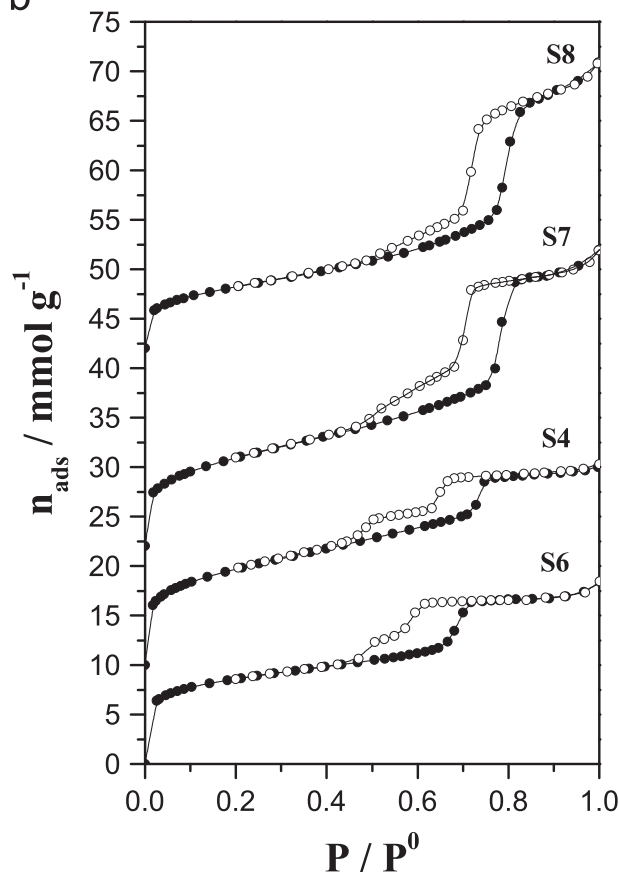

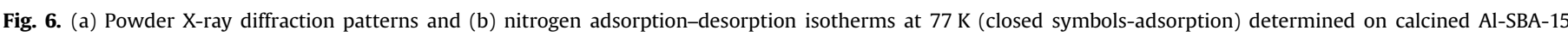

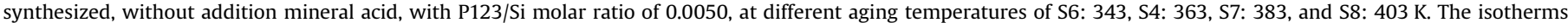
were offset vertically by 10,22 , and $42 \mathrm{mmol} \mathrm{g}^{-1}$. 
Table 2

Textural properties of Al-SBA-15 synthesized in an acid-free system with a P123/Si molar ratio of 0.050 at different aging temperatures. ${ }^{\mathrm{a}}$

\begin{tabular}{|c|c|c|c|c|c|c|c|c|c|c|c|c|c|c|}
\hline Sample & $\mathrm{Si} / \mathrm{Al}$ & $\begin{array}{l}a_{0} \\
(\mathrm{~nm})\end{array}$ & $\begin{array}{l}T \\
(\mathrm{~K})\end{array}$ & $\begin{array}{l}A_{\mathrm{BET}} \\
\left(\mathrm{m}^{2} \mathrm{~g}^{-1}\right)\end{array}$ & $\begin{array}{l}A_{\text {ext }} \\
\left(\mathrm{m}^{2} \mathrm{~g}^{-1}\right)\end{array}$ & $\begin{array}{l}V_{p} \\
\left(\mathrm{~cm}^{3} \mathrm{~g}^{-1}\right)\end{array}$ & $\begin{array}{l}V_{\text {mic }} \\
\left(\mathrm{cm}^{3} \mathrm{~g}^{-1}\right)\end{array}$ & $\begin{array}{l}V_{\text {mes }} \\
\left(\mathrm{cm}^{3} \mathrm{~g}^{-1}\right)\end{array}$ & $\begin{array}{l}V_{\text {mes, blocked }} \\
\left(\mathrm{cm}^{3} \mathrm{~g}^{-1}\right)\end{array}$ & $\begin{array}{l}V_{\text {mes, open }} \\
\left(\mathrm{cm}^{3} \mathrm{~g}^{-1}\right)\end{array}$ & $\begin{array}{l}V_{\text {micro }} \\
(\%)\end{array}$ & $\begin{array}{l}V_{\text {mes, blocked }} \\
(\%)\end{array}$ & $\begin{array}{l}D_{p} \\
(\mathrm{~nm})\end{array}$ & $\begin{array}{l}t \\
(\mathrm{~nm})\end{array}$ \\
\hline S6 & 47 & 11.8 & 343 & 702 & 25 & 0.55 & 0.10 & 0.45 & 0.24 & 0.21 & 18 & 53 & 6.8 & 5.0 \\
\hline S4 & 44 & 12.0 & 363 & 780 & 30 & 0.64 & 0.10 & 0.54 & 0.31 & 0.23 & 16 & 57 & 7.3 & 4.7 \\
\hline S7 & 41 & 13.4 & 383 & 731 & 49 & 0.89 & 0.01 & 0.88 & 0.08 & 0.80 & 1 & 9 & 8.5 & 4.9 \\
\hline S8 & 27 & 13.3 & 403 & 509 & 126 & 0.65 & 0.01 & 0.64 & 0.05 & 0.59 & 1 & 8 & 9.1 & 4.2 \\
\hline
\end{tabular}

${ }^{a}$ For notation, see Table 1 caption.

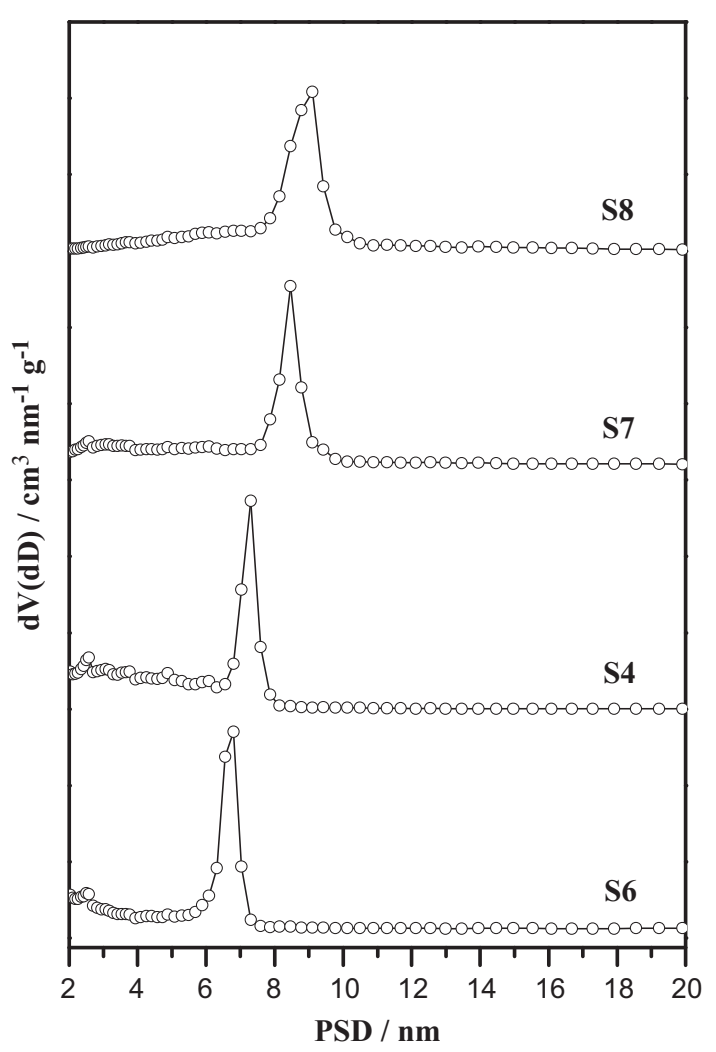

Fig. 7. NLDFT pore size distribution curves calculated from adsorption branches of Al-SBA-15 synthesized, without addition of mineral acid, with a P123/Si molar ratio of 0.0050, at different aging temperature of S6: $343 \mathrm{~K}, \mathrm{~S} 4: 363 \mathrm{~K}, \mathrm{S7}: 383 \mathrm{~K}$, and S8: $403 \mathrm{~K}$.

the reduction of P123/Si molar ratio from 0.010 to 0.0050 . This result illustrates that the aluminosilicate plug structures containing considerable microporosity were formed inside the mesopores as suggested by Van Der Voort et al. [21,22]. However, decreasing the P123/Si molar ratio even further to 0.0025 in the initial reaction solution, results in a sample (S5) exhibiting negligible micropore volume. Considering the relative slow hydrolysis and condensation of silica source as reported by Kruk et al. [29], we proposed that the aluminosilicate species with no and/or low porosity will be generated inside the straight mesopore channels in an acid-free synthesis medium with a very low P123/Si molar ratio of 0.0025 . On the other hand, it was found that the percentages of blocked mesopores to the total mesopores can be changed between $0 \%$ and $68 \%$ through a facile adjustment of P123/ Si molar ratio from 0.014 to 0.0025 , indicating that the more hydrophilic and hydrated PEO blocks (poly(ethylene oxide) sections in P123) led to the formation of larger pore and vice versa under the synthetic conditions used in this work.

In general, physical phenomena like tensile strength effect (TSE), adsorbate phase transitions, and monolayer formation can affect the isotherms of materials with hierarchical pore structures and especially influence the hysteresis loops [30]. We calculated the pore size distributions of calcined Al-SBA-15 by using the non-local density functional theory (NLDFT) model. The samples synthesized from solutions with a relatively low P123/Si molar ratio present a PSD curve with two peaks obtained from equilibrium model (SI Fig. 4a). In contrast, the relative small mesopores cannot be observed on the curve calculated from adsorption branch (Fig. 5a). In this work, the adsorption branch was selected for the calculation since it is hardly affected by TSE phenomena as reported by Groen et al. [30]. It was observed that the pore size slightly increased with the increase of the P123/Si molar ratio in the initial solution ranging from 0.0025 to 0.014 (Fig. 5a), indicating that the more hydrophilic and hydrated PEO blocks led to the formation of larger pore and vice versa under the synthetic conditions used in this work.

Fig. 4 and SI Fig. 5 show the effect of P123/Si molar ratio on the morphology of the final samples. The Al-SBA-15 samples show a continuous morphology variation from an exceedingly curved to an approximately straight rod-like particle with a decrease of the $\mathrm{P} 123 / \mathrm{Si}$ molar ratio from 0.014 to 0.0025 in the initial reaction solution. Al-SBA-15 crystallized from an initial reaction solution with the P123/Si molar ratio of 0.0025 exhibited a rougher external surface (Fig. 4c). According to these results, in an acidfree synthetic system, the P123/Si molar ratio plays an important influence on both the structural property and the morphology of the resulting materials.

To further study the formation and the structural properties of the plug structures, the XRD, $\mathrm{N}_{2}$ sorption and TEM results of plugcontaining Al-SBA-15 synthesized at various aging temperatures with the P123/Si molar ratio of 0.005 are given in Figs. 6 and 8, respectively. On one hand, increasing aging temperature up to $403 \mathrm{~K}$ can promote the formation of Al-SBA-15 with a relatively higher structural ordering, which is supported by the observation of three well-resolved peaks for the samples synthesized at 383 and $403 \mathrm{~K}$, respectively (Fig. 6a). On the other hand, distinct capillary condensation can be seen in Fig. $6 \mathrm{~b}$ on all isotherms. The capillary condensation steps slightly shifted towards higher relative pressures when raising the aging temperature from 343 to $403 \mathrm{~K}$, which is accompanied by the enlargement of mesopores from 6.8 to $9.1 \mathrm{~nm}$ (Table 2 and Fig. 7). As seen in Fig. 8, similar to that of S4 which synthesized at $363 \mathrm{~K}$, the visible plug structures in lower contrast can be seen within the mesopores of Al-SBA-15 prepared at $343 \mathrm{~K}$. Increasing aging temperature to 383 and $403 \mathrm{~K}$, the resulting Al-SBA-15 exhibits less obstructed meso-channels, indicating that a higher temperature can inhibit the formation of the plug structures. Meanwhile, the percentages of blocked mesopores for these two samples were respectively calculated as 9 and 8\%, apparently less than those of samples synthesized at relatively lower aging temperatures (Table 2). It is interesting to note that increasing aging temperature from 363 to $383 \mathrm{~K}$ led to a conspicuous variation on the mesostructures, including the increasing of unite cell form 12.0 to $13.4 \mathrm{~nm}$, the disappearance of micropores, and the enlargement of pore size from 7.3 to $8.5 \mathrm{~nm}$ (Table 2). These results can be explained with the formation of secondary pore structures in the walls of Al-SBA-15 with the pore diameter in the range of several nanomerters [37,40-42].

The careful study of the influence of aging temperature on the structural characteristics of Al-SBA-15, we found that S8 (aged at 

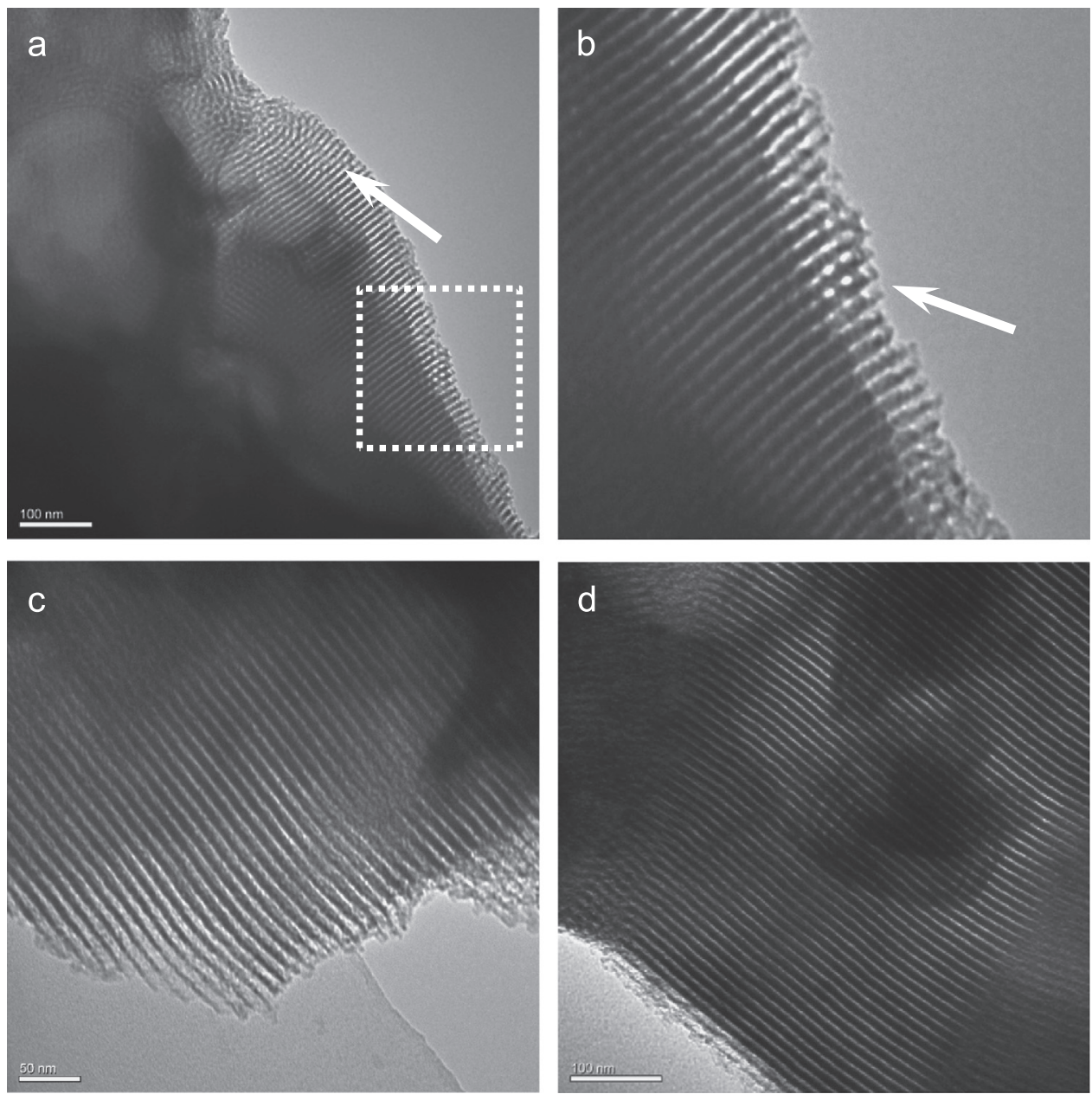

Fig. 8. Typical TEM images taken along the [110] direction of calcined Al-SBA-15, without mineral acid, with P123/Si molar ratio of 0.0050, at various aging temperature of (a), (b) $343 \mathrm{~K}$, (c) $383 \mathrm{~K}$, and (d) $403 \mathrm{~K}$. (b) is the zooming-in image of dotted square inserted in (a).

a

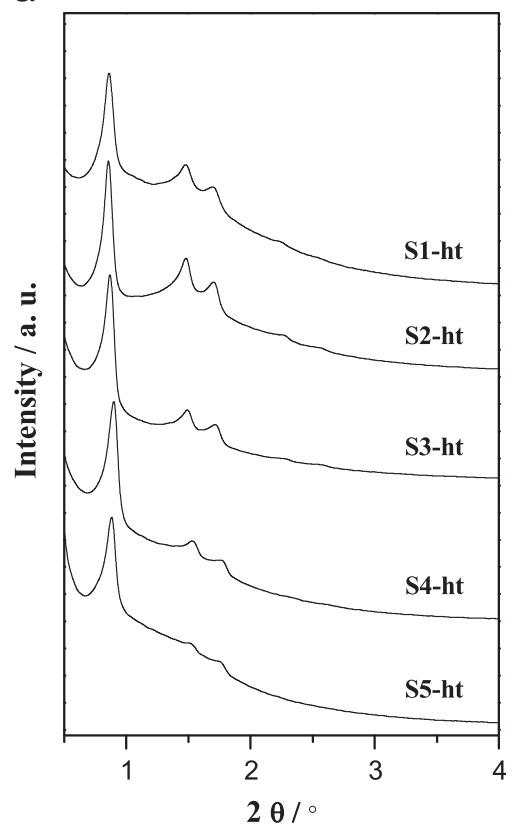

b

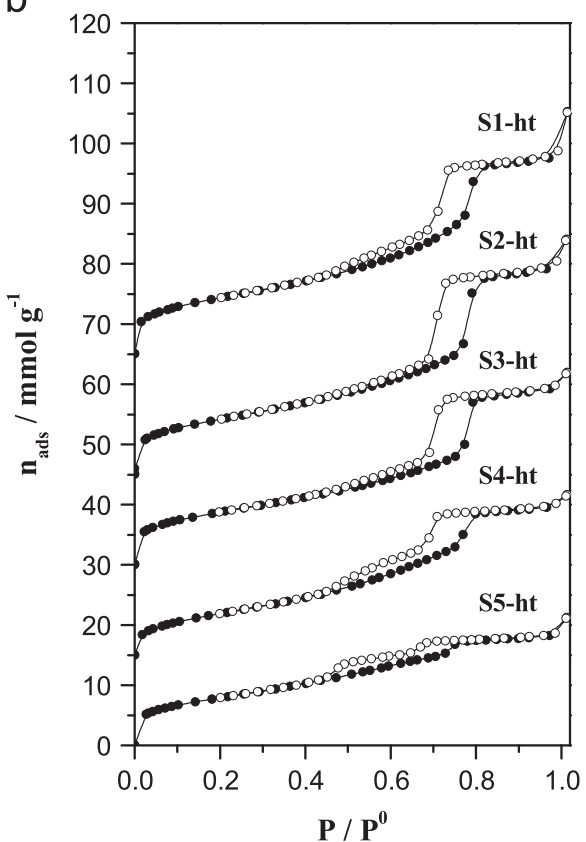

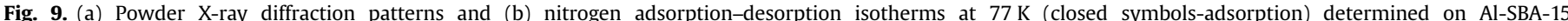
hydrothermally treated in boiling water for $100 \mathrm{~h}$. The isotherms were offset vertically by $15,30,45$, and $65 \mathrm{mmol} \mathrm{g}^{-1}$, respectively. 
$403 \mathrm{~K}$ ) displayed an exceptionally low total pore volume, small wall thickness and BET surface area. S8 consists of more undefined shaped particles compared to others (SI Fig. 7d); particles are more fragmented. According to Oswald ripening, we proposed the hydrolysis was rapid compared to recondensation at the high aging temperature of $403 \mathrm{~K}$ under the present synthetic conditions [43]. As a consequence, large amount of irregular aluminosilicate fragments formed and resulted in a significant low total pore volume of $0.65 \mathrm{~cm}^{3} \mathrm{~g}^{-1}$ for $\mathrm{S} 8$, which nevertheless possesses the largest pore diameter of $9.1 \mathrm{~nm}$ and the largest external surface area $\left(126 \mathrm{~m}^{2} \mathrm{~g}^{-1}\right)$. In contrast, samples synthesized at relatively low aging temperatures present a high microporosity, owing to the formation of large amount of plugged aluminosicate species.

As reported by Van Der Voort et al., plug structures inside the mesopores can apparently enhance the stability of the final mesostructures [22]. We studied the effect of hydrothermal treatment on the open and blocked type mesostructures of Al-SBA-15 synthesized without addition of any mineral acid, and the results are presented in Figs. 2, 4, 5 and 9 and Table 1. It can be seen from TEM and SEM results that the hydrothermal treatment did not damage the wall structures and the morphology of Al-SBA-15 (Figs. 2 and 4), indicating that the samples have a high hydrothermal stability. Simultaneously, the textural properties of plugcontaining Al-SBA-15 can be significantly modified by a mild hydrothermal post treatment. First, the enlargement in the mesopore diameter combined with the decrease of the wall thickness was observed during the hydrothermal treatment for all samples (Fig. 5b and Table 1). Second, the absence of micropores in the hydrothermally treated Al-SBA-15 can be due to the enlargement of micropores in the wall. It worth noting that hydrothermal treatment can dissolve the plug structures inside mesopores to form more "open" mesostructures for plug-containing Al-SBA-15. As for the Al-SBA-15 synthesized from the initial reaction solution with a P123/Si molar ratio higher than 0.0075 (S2 and S3), $100 \mathrm{~h}$ hydrothermal treatment can completely dissolve the plug species, subsequently open all channels. Even for Al-SBA-15 synthesized from the reaction solution with a P123/Si molar ratio of 0.0025 , the mild hydrothermal treatment used in this work can also "open" around $37 \%$ blocked mesopores ( calculate from formula of (68\%$43 \%) / 68 \%$ ), in spite of its no and/or low porous plug structure. Of course, the percentage of the "open-form" mesopores can be further increased through other harsher hydrothermal posttreatments or combined with washing the sample in a basic solution to extract more plug structures from the mesopores. On the other hand, the dissolution of plug structures during the mild hydrothermal treatment also improves structural ordering of Al-SBA-15. Compared to the as-synthesized samples (Fig. 1a), the hydrothermally treated Al-SBA-15 exhibited a better defined (110) diffraction peak. The clear (100) diffraction signals could be related to the enhanced contrast between the wall structures and "open" mesopores. In addition, the Int.(110)/Int.(200) ratios were found increased for Al-SBA-15 hydrothermally treated in a boiling water for $100 \mathrm{~h}$, indicating a decrease in wall thickness (Table 1), as suggested for the hexagonal mesostructure of MCM-41 [44].

\section{Conclusion}

Al-SBA-15 containing plug structures inside mesopores with highly structural ordering and hydrothermal stability was directly synthesized in a synthetic medium without containing any additional mineral acid. By controlling the P123/Si molar ratio in the range of $0.014-0.0025$ in the initial reaction solution, the Si/Al molar ratio of the resultant sample can be easily adjusted in the range of 32-49 with the presence of predominantly 4-coordinated $\mathrm{Al}$ in the final Al-SBA-15. As for the structural property, $0-68 \%$ of the mesopores of the total pore volume could be blocked by the plug structures. Meanwhile, the filling of mesopores lead to the decrease of BET surface area and total pore volume resulting from the formation of plugs with relatively poor microporosity. Increasing hydrothermal treatment temperature higher than $363 \mathrm{~K}$ can effectively suppress the formation of plug structures even in the synthetic solution with a low P123/Si molar ratio of 0.0050 . More importantly, we proposed a model interpreting the observation by TEM of alternate defined areas of higher and lower contrast inside the mesopores as the strong evidence of isolated microporous aluminosilicate plugs inside the channels. We also showed that it is easy to finely adjust the pore structure of Al-SBA- 15 by a moderate hydrothermal post-treatment that enables the controlled dissolution of the plug species to a desired target.

\section{Acknowledgments}

This work was supported by a Grant of National Natural Science Foundation of China (51202134) and Shangdong Province Young and Middle-Aged Scientists Research Awards Fund (BS2012CL027). The authors gratefully acknowledge the help of Mr. Biao Xu for the $\mathrm{N}_{2}$ sorption measurement and sincerely thank Dr. Charlotte Bonneau for the valuable discussion. This study was partially supported by 100-Talent Project of Chinese Academy of Science Foundation (Grant KJCX2-EW-H05).

\section{Appendix A. Supporting information}

Supplementary data associated with this article can be found in the online version at http://dx.doi.org/10.1016/j.jssc.2013.04.040.

\section{References}

[1] B.J. Scott, G. Wirnsberger, G.D. Stucky, Chem. Mater. 13 (2001) 3140-3150.

[2] A. Stein, Adv. Mater. 15 (2003) 763-775.

[3] A. Taguchi, F. Schüth, Microporous Mesoporous Mater. 77 (2005) 1-96.

[4] A. Corma, Chem. Rev. 97 (1997) 2373-2419.

[5] S. Wang, Microporous Mesoporous Mater. 117 (2009) 1-9.

[6] A. Popat, S.B. Hartono, F. Stahr, J. Liu, S. Qiao, G. Lu, Nanoscale 3 (2011) 2801-2818.

[7] K.K. Qian, R.H. Bogner, J. Pharm. Sci. 101 (2012) 444-463.

[8] C.T. Kresge, M.E. Leonowicz, W.J. Roth, J.C. Vartuli, J.S. Beck, Nature 359 (1992) 710-712.

[9] J.S. Beck, J.C. Vartuli, W.J. Roth, M.E. Leonowicz, C.T. Kresge, K.D. Schmitt, C.T.-W. Chu, D.H. Olson, E.W. Sheppard, S.B. McCullen, J.B. Higgins, J.L. Schlenker, J. Am. Chem. Soc. 114 (1992) 10834-10843.

[10] D. Zhao, J. Feng, Q. Huo, N. Melosh, G.H. Fredickson, B.F. Chmelka, G.D. Stucky, Science.279 (1998) 548-552.

[11] D. Zhao, Q. Huo, J. Feng, B.F. Chmelka, G.D. Stucky, J. Am. Chem. Soc. 120 (1998) 6024-6036.

[12] X. Cui, W.-C. Zin, W.-J. Cho, C.-S. Ha, Mater. Lett. 59 (2005) 2257-2261.

[13] D.P. Serrano, J. Aguado, G. Morales, J.M. Rodriguez, A. Peral, M. Thommes, J.D. Epping, B.F. Chmelka, Chem. Mater. 21 (2009) 641-654.

[14] N.D. Hould, S. Kumar, M. Tsapatsis, V. Nikolakis, R.F. Lobo, Langmuir 26 (2010) 1260-1270.

[15] K. Möller, B. Yilmaz, U. Müller, T. Bein, J. Am. Chem. Soc. 133 (2011) 5284-5295.

[16] K. Möller, B Yilmaz, U. Müller, T. Bein, Chem. Mater. 23 (2011) 4301-4310.

[17] W. Zhang, T.R. Pauly, T.J. Pinnavaia, Chem. Mater. 9 (1997) 2491-2498.

[18] K. Ikari, K. Suzuki, H. Imai, Langmuir 20 (2004) 11504-11508.

[19] X. Wang, W. Li, G. Zhu, S. Qiu, D. Zhao, B. Zhong, Microporous Mesoporous Mater. 71 (2004) 87-97.

[20] F. Zhang, Y. Yan, Y. Meng, Y. Xia, B. Tu, D. Zhao, Microporous Mesoporous Mater. 98 (2007) 6-15.

[21] P. Van Der Voort, P.I. Ravikovitch, K.P. De Jong, A.V. Neimark, A.H. Janssen, M. Benjelloum, E. Van Bavel, P. Cool, B.M. Weckhuysen, E.F. Vansant, Chem. Commun. (2002) 1010-1011.

[22] P. Van Der Voort, P.I. Ravikovitch, K.P. De Jong, M. Benjelloum, E. Van Bavel, A.H. Janssen, A.V. Neimark, B.M. Weckhuysen, E.F. Vansant, J. Phys. Chem B 106 (2002) 5873-5877.

[23] B.-H. Min, E.-Y. Jeong, M. Thommes, S.-E. Park, Chem. Commun. 47 (2011) 4673-4675. 
[24] Z. Jia, Y. Zhao, Collect. Czech. Chem. Commun. 76 (2011) 39-49.

[25] Z. Wu, H. Wang, T. Zhuang, L. Sun, Y. Wang, J. Zhu, Adv. Funct. Mater. 18 (2008) 82-94.

[26] N. Lin, J. Yang, Z. Wu, H. Wang, J. Zhu, Microporous Mesoporous Mater. 139 (2011) 130-137.

[27] Z. Yuan, J.-L. Blin, B.-L. Su, Chem. Commun. (2002) 504-505.

[28] V. Meynen, P. Cool, E.F. Vansant, Microporous Mesoporous Mater. 104 (2007) 26-38.

[29] M. Kruk, M. Jaroniec, S.H. Joo, R. Ryoo, J. Phys. Chem. B 107 (2003) 2205-2213.

[30] J.C. Groen, L.A.A. Peffer, J. Pérez-Ramírez, Microporous Mesoporous Mater. 60 (2003) 1-17.

[31] S. Lin, L. Shi, M.M.L. Ribeiro Carrott, P.J.M. Carrott, J. Rocha, M. Li, X. Zou, Microporous Mesoporous Mater. 142 (2011) 526-534.

[32] S.Y. Chen, L.Y. Jang, S. Cheng, Chem. Mater. 16 (2004) 4174-4180.

[33] S.Y. Chen, H.D. Tsai, W.T. Chuang, J.J. Lee, C.Y. Tang, C.Y. Lin, S. Cheng, J. Phys. Chem. C 113 (2009) 15226-15238.
[34] R.K. Iler, The Chemistry of Silica, Wiley, New York, 1971.

[35] S. Jun, R. Ryoo, J. Catal. 195 (2000) 237-243.

[36] A. Davidson, Curr. Opin. Colloid Interface Sci. 7 (2002) 92-102.

[37] M. Kruk, M. Jaroniec, C.H. Ko, R. Ryoo, Chem. Mater. 12 (2000) 1961-1968.

[38] S. Jun, S.H. Joo, R. Ryoo, M. Kruk, M. Jaroniec, Z. Liu, T. Ohsuna, O. Terasaki, J. Am. Chem. Soc. 122 (2000) 10712-10713.

[39] A. Galarneau, N. Cambon, F. Di Renzo, R. Ryoo, M. Choi, F. Fajula, New J. Chem. 27 (2003) 73-79.

[40] F. Kleitz, F. Bérubé, R. Guillet-Nicolas, C.-M. Yang, M. Thommes, J. Phys. Chem. C 114 (2010) 9344-9355.

[41] A. Galarneanu, H. Cambon, F. Di Renzo, F. Fajula, Langmuir 17 (2001) 8328-8335.

[42] M. Impéror-Clerc, P. Davison, A. Davison, J. Am. Chem. Soc. 122 (2000) $11925-11933$.

[43] W. Yang, F. Gao, G. Wei, L. An, Cryst. Growth Des. 10 (2010) 29-31.

[44] B.P. Feuston, J.B. Higgins, J. Phys. Chem. 98 (1994) 4459-4465. 